\title{
Comment
}

\section{Projeto Político Pedagógico: \\ Uma estratégia para o sucesso da Gestão Escolar}

\author{
Maria Zuleide de Lima Nogueira ${ }^{\text {; }}$ Sislândia Maria Ferreira Brito ${ }^{2}$
}

\begin{abstract}
Resumo: Este artigo comenta sobre a educação, seu processo de evolução e o funcionamento interno da escola à partir do Projeto Político Pedagógico (PPP), avaliando cada ator da Gestão e sempre enfatizando a importância do planejamento para que seja adequado e democrático. A exposição clara dos objetivos a serem alcançados e, a existência de uma aliança entre a comunidade e a escola, também são enfocadas como facilitadoras no processo. A proposta é discutir a inclusão dos métodos culturais de ensino, bem como adaptações nas avaliações pedagógicas, de forma a que a escola exerça sua função social. Discutir-se-á sobre a importância que o Projeto Político Pedagógico na dinâmica escola e comunidade.
\end{abstract}

Palavras-chave: Projeto Político Pedagógico. Educação. Gestão Escolar.

\section{Pedagogical Political Project: A strategy for the success of the School Management}

\begin{abstract}
This article comments on education, its evolution process and the school's inner workings from the Pedagogic Political Project (PPP), evaluating each actor Management and always emphasizing the importance of planning for appropriate and democratic. A clear statement of objectives to be achieved and the existence of an alliance between the community and the school are also focused as facilitators in the process. The proposal is to discuss the inclusion of cultural methods of teaching, as well as adaptations in pedagogical assessments, so that the school performs its social function. We will discuss about the importance of the Political Pedagogical Project in dynamic school and community.
\end{abstract}

Keywords: Pedagogical Political Project. Education. School management.

\section{Introdução}

O objetivo deste trabalho é discutir a evolução educacional no Brasil, propondo métodos que devem ser utilizados, para que o Brasil se torne um país com níveis melhores em educação. Reflete a importância do Planejamento para investimentos mais adequados, programações de capacitação profissional e logística mais eficiente da escola.

\footnotetext{
${ }^{1}$ Programa de Mestrado em Educação da Anne Sullivan University. E-mail: zuleide.lima01 @ hotmail.com;

${ }_{2}^{2}$ Professora Efetiva da Universidade Regional do Cariri - URCA do Departamento de Educação. Graduada em Pedagogia, Especialista em Multidimensionalidade do Ensino da Arte e Formação do Arte/Educador pela Universidade Regional do Cariri-URCA. É Doutora Pelo Programa de Doutorado em Artes Visuais e Educação do Centro de Educação da Universidade de Sevilla - Espanha. É associada ao InSEAInternational Society for Education Through Art (Sociedade Internacional de Educação pela Arte). É membro da Rede Ibero Americana de Educação Artística.
} 
A principio, é de fundamental importância abordar sobre a educação e o método nacional utilizado para o ensino nas escolas, além disso, a uma preocupação quanto a falta de investimento nesse âmbito, visto que o Brasil é um país muito rico em relação a parte financeira e seria irrelevante o investimento adequado neste setor, afinal, ele é a base para que haja melhorias exatas para a sociedade.

A criação e a decisão das escolas em aderirem ao Projeto Político Pedagógico (PPP) é um ato que exige disposição, mas com uma visão ampla e que se for coordenada de forma adequada os resultados obtidos por elas logo será de acordo com o que foi planejada, afinal a inserção da cultura pedagógica em uma escola faz com que exista uma ligação entre seus gestores e a comunidade.

Inicialmente neste trabalho buscou-se buscar conceitos de vários doutrinadores para que não haja duvidas quanto a importância do PPP, apresentando os procedimentos metodológico da pesquisa, mostrando a realidade para que o projeto seja realizado com sucesso, atendendo as demandas sociais, culturais, pedagógicas e políticas, promovendo a melhoria no ensino.

A organização e gestão escolar serão abordadas separadamente, mas com a unção de apresentar os membros de uma escola e a função que cada um tem, assim como os métodos que são utilizados por eles para que garantam um ensino de qualidade para os educandos e ao mesmo tempo mantenham um bom relacionamento com a comunidade.

A oportunidade que é dada aos jovens e adultos que não tiveram oportunidade de estudar durante o período rotineiro, com a criação de novos programas escolares, que visam inserir essas pessoas ao acesso educacional, foram executado e que dão certo, mas até mesmo neste tipo de programa escolar é necessário a inclusão do ensino pedagógico, servindo como estimulo para esses jovens e adultos, onde a maioria trabalha durante o dia e chegam cansados, mas como pretendem evoluir no nível escolar, eles usam a vontade para que assim aconteça.

Salientando que o PPP é apenas um esboço realizado por toda a equipe escolar, que se for planejado de forma adequada, traçando o seu destino final, objetivos e as atividades a ser desenvolvido, consequentemente ele irá sair do planejamento para ser executado de forma adequada, atingindo assim os seus objetivos. 
Id on Line Revista Multidisciplinar e de Psicologia

Id on Line Multidisciplinary and Psycology Journal

Em resumo, o trabalho irá mostrar detalhadamente as divisões para um entendimento mais adequado a respeito do assunto, quão importante é as escolas tirarem os projetos de dentro das gavetas e coloca-los em prática, ajudando em uma educação de qualidade.

\section{Plano de Educação no Brasil}

A educação é a base de tudo para uma pessoa. É a ponte para um caminho do conhecimento e de fundamental importância, pois uma capacidade cultural que ganha destaque em qualquer parte do universo, um indivíduo que busca o ensino sempre em sua vida, alcança os seus objetivos sempre que os põem como metas.

O conceito de educação sofreu influência do nativismo e do empirismo. O primeiro era entendido como o desenvolvimento das potencialidades interiores do homem, cabendo ao educador apenas exterioriza-las, e o segundo era o conhecimento que o homem adquiria através da experiência. (MARTINS, 2004, p 13).

Esse instrumento é o grande investimento dos países desenvolvidos e que se destacam quanto as descobertas e estudos de qualquer ramo, afinal, adquirir conhecimento é uma característica fantástica e com a evolução e exigências do mercado de trabalho, só consegue se manter nele, aquelas pessoas que visam a atualização relacionada aos estudos e ao conhecimento intelectual, a absolvição de inovações e atualização de aprendizagens e técnicas educacionais.

A educação deve, segundo Kant, cultivar a moral, despertando para que o homem tome consciência de que ela deve estar presente em todas as ações de sua vida, em todo o seu desenvolvimento, em todo o ser, e por efeito, deitando raízes sobre o direito, que não subsiste sem a moral. (MUNIZ, 2002, p. 38).

Vejamos o que diz o Ministério da Educação (MEC) a respeito da conceituação de educação:

\footnotetext{
A Educação Básica é direito universal e alicerce indispensável para a capacidade de exercer em plenitude o direto à cidadania. É o tempo, o espaço e o contexto em que o sujeito aprende a constituir e reconstituir a sua identidade, em meio a transformações corporais, afetivo-emocionais, sócio emocionais, cognitivas e socioculturais, respeitando e valorizando as diferenças. Liberdade e pluralidade tornam-se, portanto, exigências do projeto educacional. (MEC, 2013).
} 
Fácil percebermos quão importante é o investimento em uma educação de qualidade, afinal essa palavra é à base de tudo, conhecimento é um bem que levamos por toda vida, mas é necessário que as pessoas tenham acesso a uma educação de qualidade e que possibilite um sucesso intelectual e profissional adequado.

Observam-se grandes falhas relacionadas ao ensino, mas a cada atualização da Constituição Federal o plano de ensino era reformulado para chegar a um nível mais elevado, a burguesia e a alta sociedade tinham condições de enviar seus filhos ao exterior para que esses pudessem se tornar pessoas com o ensino especializado, dentro das profissões mais cobiçadas que existiam.

A educação como forma de ensino, ou seja, o repasse de conhecimento aos demais se iniciou desde quando o Brasil era uma colônia de Portugal, onde os Jesuítas ensinavam o catolicismo aos indígenas, os padres não possuíam especialização para exercer tal função, bastava saber ler e escrever. Era uma modalidade de assegurar o domínio português sob os índios e escravos.

\begin{abstract}
Até os anos 20, a educação brasileira comportou-se como um instrumento de mobilidade social. Os estratos que detinham o poder econômico e político utilizavamna como distintivo de classe. As camadas médias procuravam-na como a principal via de ascensão social, prestígio e integração com os estratos dominantes. Nesta sociedade, ainda não havia uma função «educadora» para os níveis médio e primário, razão pela qual eles não mereceram atenção do Estado, senão formalmente. A oferta de escola média, por exemplo, era incipiente, restringindo-se, praticamente, a algumas iniciativas do setor privado (ROMANELLI, 1983, p.32).
\end{abstract}

Foi durante o período em que o Brasil se tornou uma República a educação e a busca pelo conhecimento começou a se destacar, na constituição de 1934 já estabeleceu um plano de educação que seria obrigatório e gratuito e o ensino religioso já não era obrigatório e a cada reforma constitucional a educação foi se destacando e ganhando mais importância.

A severidade nas escolas era uma problemática, pois as crianças passavam a maior parte do dia nelas e os professores tinham autoridade de impor sanções em caso de desobediência ou comportamento inadequado, isso ocorria porque os pais não desfrutavam de tempo para educar seus filhos, assim essa autonomia era repassada aos professores que assim faziam.

Mas com a promulgação da Constituição Federal de 1988, ocorreu uma reforma bem significativa regida em todo o território brasileiro, introduzindo inovações e compromisso com 
Id on Line Revista Multidisciplinar e de Psicologia

Id on Line Multidisciplinary and Psycology Journal

a educação, com o objetivo de gratuidade desde o ensino fundamental até a universidade, além de se basear na erradicação do analfabetismo.

A própria Constituição Federal em seu artigo $5^{\circ}$ assegura o direito à educação sem nenhum tipo de discriminação, onde o Estado tem obrigação de garantir esse direito de todo cidadão brasileiro, cuidando minuciosamente deste assunto, nossa Carta Magna ainda trata-o com exclusividade.

“A educação, direito de todos e dever do Estado e da família, será promovida e incentivada com a colaboração da sociedade, visando ao pleno desenvolvimento da pessoa, seu preparo para o exercício da cidadania e sua qualificação para o trabalho." (artigo 205, CF/88).

Esse direito à educação não se impõe apenas ao ato de matricular a criança em uma escola, mas de assegurar as garantias quanto a qualidade de ensino e formas de manterem interesse pelo conhecimento, uma educação de qualidade há uma redução quanto as desigualdades sociais, com a permanência e o sucesso escolar e futuramente profissional.

De acordo com Silva (2000, p. 314-315) que relata sobre o artigo 205 da Constituição Federal estabelecendo três objetivos básicos da educação: pleno desenvolvimento da pessoa, preparo da pessoa para o exercício da cidadania e qualificação da pessoa para o trabalho.

Dentro de sua pesquisa iremos analisar e defender cada um dos objetivos do Brasil dentro de sua Constituição baseada na educação. Onde o pleno desenvolvimento da pessoa e relacionado ao empenho pessoal de cada um, em busca de seus sonhos, se opta por estudar amplamente e minuciosamente ou de apenas cumprir um tipo de roteiro na vida de muitos brasileiros, que é praticar os atos da vida escolar sem interesse, apenas por fazer parte de um cotidiano

Ainda com ênfase no desenvolvimento pessoal, o conhecimento pelo Estado onde cada indivíduo tem um papel fundamental dentro da integração da sociedade estatal, cabendo ao primeiro disponibilizar o ensino gratuito e de qualidade. E, ao último, o interesse e a busca incessante pelo saber, uma evolução individual, respeitando ainda a dignidade humana.

Outro objetivo da Constituição Federal é o preparo da pessoa para o exercício da cidadania, onde cabe ao Estado ofertar e assegurar gratuitamente para todos os cidadãos o direito a uma educação de qualidade, para que todas as pessoas que não possuem condições financeiras de praticar um ensino privado usufruam de um ensino qualificado. 
Id on Line Revista Multidisciplinar e de Psicologia

Id on Line Multidisciplinary and Psycology Journal

Finalizando com a qualificação profissional da pessoa, ou seja, para que depois de praticar e concluir seus estudos na escola tenha direito, mas dentro de seus esforços para que assim entre em uma instituição de ensino superior e após a conclusão desta, esteja apto ao mercado de trabalho, dentro das exigências para que todo o ensino e conhecimento que lhe foi passado seja posto em prática.

O Brasil vem evoluindo gradativamente quanto à educação, mas devido a precariedade no ensino, o baixo estímulo dado aos professores que são os grandes astros desse universo de aprendizagem, afinal, são eles que repassam seus conhecimentos aos alunos e estão sempre em busca do saber para que assim continuem fazendo, faz com que o país não seja um bom investidor no setor da educação, e essa afirmativa se torna correta quando em noticiários e pesquisas apontam a precariedade dos alunos em relação as notas de testes que avaliam o nível de conhecimento e afins.

Mas não podemos esquecer-nos de projetos educacionais e que possuem grande relevância ao serem postos em praticas e os resultados são obviamente positivos, que é a inclusão dos adultos nas escolas, aqueles que durante a infância e adolescência não tiveram oportunidade de frequentar uma sala de aula, mas que devido alguns projeto como o Ensino de Jovens e Adultos (EJA) disponibiliza horários para que essas pessoas concluam o ensino médio e logo após, possam integrar uma Instituição de Ensino Superior (IES).

O Estado disponibiliza a educação gratuita e o acesso escolar a todas as pessoas, assim como criou métodos de ensino e projetos para inclusão de pessoas adultas que não tiveram oportunidade de um ensino na época exata, mas a importância que se dá é a qualidade deste ensino ofertado tanto para as crianças, quanto para os adolescentes e também aos adultos.

Para que haja uma organização quanto à administração educacional, o país conta com o apoio do Ministério da Educação (MEC) que organiza e financia o sistema federal de ensino, prestando essa assistência aos estados, Distrito Federal e aos municípios, ou seja, recai sob cada um deles a responsabilidade de manusear seus sistemas de ensino, qualidade e até mesmo a fiscalização quanto à idade adequada para que as crianças iniciem seus estudos.

A área da educação e, em especial, a escola têm papel fundamental a desempenhar. É necessário e possível caminhar no sentido da democratização do Estado, por meio da democratização da escola, substituindo seu conteúdo e sua concepção, calcada em valores e 
Id on Line Revista Multidisciplinar e de Psicologia

Id on Line Multidisciplinary and Psycology Journal

interesses de determinados grupos, pelos valores e interesses dos seus usuários. (Portal MEC, 2006).

Então, o Ministério da Educação possui um grande poder de administrar o lado financeiro e de execução do ensino em todo âmbito nacional, onde lançou em abril de 2007 o Plano de Desenvolvimento da Educação, com o intuito de repercutir positivamente a qualidade de ensino.

Foi o MEC que apresentou a proposta aprovada do salário educacional, com o passar do tempo ele deixou de ser um ministério da educação e do desporto, mas somente ligada à educação a respaldava sob si o manuseio quanto as competências de politica nacional de educação, educação infantil, educação em geral, incluindo o ensino fundamental, ensino médio, ensino superior, ensino de jovens e adultos, educação profissional, educação profissional, pesquisa e extensão universitária, magistério, assistência financeira a famílias carentes para a escolarização de seus filhos ou dependentes. (WIKIPEDIA, 2016).

Infelizmente se formos comparar a qualidade da educação entre escolas públicas e as escolas privadas são perceptíveis o nível de aprendizagem, afinal, há muitas falhas na rede de ensino público, onde o próprio professor que é a autoridade máxima de uma sala de aula acaba perdendo sua autonomia e não é valorizado da forma correta.

O tema relacionado à educação possui uma magnitude considerável, sendo um assunto respeitado a nível universal, onde há uma parceria mutua entre o Estado que tem como obrigação a oferta gratuita independentemente de qualquer distinção e a família, principalmente os pais e responsáveis pelas crianças e adolescentes a mostrarem aos seus filhos a importância irrelevante que a educação possui e que a busca pelo saber sempre será o maior bem que pode uma pessoa carregar.

Mas apesar de alguns avanços quanto à diminuição na taxa de analfabetismo no Brasil, muito há do que se falar em melhoria, a qualidade deve ser sempre superior para que a desigualdade seja amenizada. Profissionalizando e capacitando os professores, visar sempre um ensino de qualidade avaliado e aprovado pelo MEC, dentre outras características benéficas.

A valorização do professor, como o papel que é de fundamental importância para o ensino deve ser posta em prática, afinal, todas as pessoas que se realizam e se destacam profissionalmente já passou por uma sala de aula, os professores precisam ter o seu papel 
destacado, uma valorização tanto cultural e respeitosa, quanto a valorização financeira pelo papel tão importante exercido por ele.

$\mathrm{Na}$ teoria o território nacional tem avançado e se tornado um país com um plano educacional defendido em sua Carta Magna, mas o que realmente importa é a qualidade da educação que é passada as crianças e adolescentes no período escolar, o que está acontecendo é que eles terminam os estudos e não estão aptos a entrarem em uma Instituição de Ensino Superior de qualidade.

Todo ano uma multidão de jovens parte para os exames vestibulares como soldados para a guerra. Os que vencem o funil seletivo são considerados heróis. Porém, menos que $65 \%$ deles concluirão o curso. A contradição entre a árdua luta pelo ingresso na graduação e a facilidade com que é abandonada é óbvia. (...) A desistência causada pela desconfiança de haver se enganado na escolha profissional também é tão frequente que cabe perguntar se o erro não está, antes, no fato da graduação, no Brasil, pecar pela especialização precoce, justo numa época em que as fronteiras entre as carreiras são cada vez menos definidas.

Muitas ocupações, hoje, exigem domínio de disciplinas ainda separadas em diferentes cursos, o que torna urgente a flexibilização curricular e a criação de cursos básicos precedendo a especialização. (Jornal O Globo, 2000).

Sistemas de cotas forma criados com o objetivo de incluir os jovens negros, de baixa renda, entre outros, em faculdades e universidades, mas será que essa é a solução? O investimento em uma educação e ensino de qualidade irá fazer com que o Brasil realmente apresente mudanças, se destacando entre os melhores, solucionando os problemas e transformando verdadeiramente os índices que não possuem tanta credibilidade.

\section{Organização Escolar}

Será analisado qual o procedimento e o papel de cada gestor dentro do âmbito escolar, mas sempre envolvendo a participação da sociedade, visto que esta é o objetivo de uma evolução considerável para o quadro educacional brasileira. Buscando apresentar respostas se cada escola está cumprindo com o seu papel social e com resultados positivos de ensino.

Toda instituição de ensino precisa de uma estrutura organizada internamente, prescrita no Regimento escolar ou em legislações especificas, são as funções que cada membro e funcionário da escola exerce, onde cada uma dessa função tem sua importância, para o bom funcionamento.

Dentro dessa composição interna estão os conselheiros, a diretoria escolar, os coordenadores ou assistentes de diretores, professores, alunos, os pais e a comunidade, tem o 
Id on Line Revista Multidisciplinar e de Psicologia

Id on Line Multidisciplinary and Psycology Journal

setor pedagógico, conselheiros de classe e de coordenação, cada um exerce um papel fundamental para que haja um bom funcionamento da instituição de ensino.

O Conselho da Escola é responsável pelas atribuições consultivas, deliberativas e fiscais, ou seja, é a parte que cuida da legislação estadual e municipal, fazendo funcionar o Regimento Escolar. Esse Conselho é escolhido no inicio do ano letivo, com participação de docentes e membros especialistas em educação, podem ser formados até pelos alunos ou seus pais, também conhecido como colegiado, democratizando as relações de poder.

O diretor escolar é aquele responsável pela coordenação, organização e direcionamento de todas as atividades praticadas nas escolas, inclusive cabe a ele aderir o projeto político pedagógico para escola que lhe cabe responsabilidade, sempre agindo dentro da lei com decisões que visam beneficiar a qualidade de ensino escolar e a comunidade de modo geral.

O bom relacionamento do diretor com os demais membros que compõem a banca escolar é de suma importância para que trabalhem juntos com o objetivo de melhorias e avanços em campos de pesquisas educacionais, ele é responsável pelo bom funcionamento de sua escola.

É todas as ações que fará é bom que seja com um processo democrático, com o apoio de sua equipe, sempre informando os procedimentos e contando com a opinião dos demais, visto que os resultados de seus procedimentos irão recair sobre todos, principalmente a forma e qualidade de ensino repassado aos alunos.

A coordenação ou os assistentes dos diretores tem o papel de auxiliar em suas ações e fazendo a substituição do diretor sempre que este precisar se ausentar, desempenhando as mesmas funções como substituto, sua existência dentro da gestão escolar é de grande importância, afinal, qualquer órgão em que seu principal chefe se ausente é necessário ter um substituto para responder na ausência dele.

A secretaria escolar tem uma importância fundamental, que é cuidar de toda parte burocrática da escola, como a documentação, escrituração e as correspondências das escolas, dos docentes, alunos e os outros funcionários, esse setor cuida das matriculas e da quantidade existente para a comunidade.

O professor é o responsável pelo ensino repassado aos alunos, onde estes são os que possuem mais contato com aqueles na escola, o professor, no Brasil não é muito valorizado, não apenas financeiramente, mas quanto a sua qualidade, importância e especialização, caso 
que fere os princípios primordiais para que a rede pública de ensino tenha uma evolução e um crescimento esperado.

Então o corpo docente da escola é o conjunto de professores em exercício nela, que tem como função a realização do principal objetivo escolar, que é o ensino. Sobre eles também recai a responsabilidade de participar da elaboração do plano escolar ou o projeto político pedagógico, que são realizados na escola como uma ferramenta fundamental.

O processo de organização educacional dispõe de elementos constitutivos que são, na verdade, instrumentos de ação mobilizados para atingir os objetivos escolares. Tais elementos ou instrumentos de ação são:

Planejamento: processo de explicitação de objetivos e antecipação de decisões para orientar a instituição, prevendo-se o que se deve fazer para atingi-los;

Organização: Atividade através da qual se dá a racionalização dos recursos, criando e viabilizando as condições e modos para se realizar o que foi planejado;

Direção/Coordenação: Atividade de coordenação do esforço coletivo do pessoal da escola;

Formação continuada: Ações de capacitação e aperfeiçoamento dos profissionais da escola para que realizem com competência suas tarefas e se desenvolvam pessoal e profissionalmente;

Avaliação: comprovação e avaliação do funcionamento da escola.

FONTE: $\quad$ http://www.acervodigital.unesp.br/bitstream/123456789/32/3/LDB_Gest\%C3\%A3o.pdf (visitado em 10 de junho de 2016, às 14:01).

Um trabalho coletivo realizado de forma adequado irá apresentar resultados positivos e beneficiando o seu desempenho e a qualidade de ensino.

\section{Atual Gestão Escolar No Brasil}

A escola é um lugar de convívio social dentro da democracia envolvendo os alunos e seus familiares, professores, a gestão escolar e os outros membros da comunidade sempre apresentando opiniões para que haja uma melhoria no processo educacional para o Brasil.

A instituição de ensino tem como sua responsabilidade a educação formal dos educandos, direcionando uma boa educação e organizando os processos de ensino adequado e bem aplicado, atendendo as necessidades de cada um dentro da sociedade, possibilitando e facilitando o ingresso pessoal dentro delas, mas deverá seguir os órgãos competentes e responsáveis pela fiscalização de seus serviços.

(...) democracia integral seria o sistema político que garante a cada um e a todos os cidadãos a participação ativa e criativa, enquanto sujeitos, em todas as esferas de poder e de saber da sociedade; o sistema que garante a cada um e a todos o direto de sermos coautores do mundo. (ARRUDA e BOFF, 2000, p. 19). 
A gestão escolar é responsável pelo estimulo ao ensino e a qualidade no oferecimento dela, desenvolvendo uma visão mais ampla da educação e do ensino pedagógico, a gestão pedagógica é uma relação com a organização e o planejamento educacional, utilizando uma metodologia em ensino com intensidade e oferecendo interações e mudanças atrativas no sentido de aprendizagem.

Gestão educacional corresponde ao processo de gerir a dinâmica do sistema de ensino como um todo e de coordenação das escolas em especifico, afinado com as diretrizes e políticas educacionais públicas, para implementação das políticas educacionais e projetos pedagógicos das escolas compromissados com os princípios da democracia e com métodos que organizem e criem condições para um ambiente educacional autônomo (soluções próprias, no âmbito de suas competências) de participação e compartilhamento (tomada conjunta de decisões e efetivação de resultados), autocontrole (acompanhamento e avaliação com retorno de informações) e transparência (demonstração pública de seus processos e resultados). (LÜCK, 2006, p.35).

Para que as ações sejam elaboradas e projetadas pela escola é necessário visar à eficiência deste procedimento, uma democratização política dentro da escola, com uma gestão adequada, com sua própria autonomia, mas com democratização. Primeiro a equipe deverá montar um plano de educação, envolvendo toda a sua equipe e toda a comunidade na qual ela faz parte, irá transformar a escola em um espaço de aprendizagem para todos, mobilizando novas construções de trabalho com a sociedade respeitando e comprovando a grande importância que a educação tem a cultura e seus valores primordiais, buscando uma escola melhor para todos.

A gestão escolar tem uma área ampla de atuação, e precisa de meios para realizar suas finalidades, como os princípios, diretrizes e objetivos educacionais, com qualidade social e atendendo o bem a comunidade, respeitando e promovendo o acesso à educação, com praticas educativas contanto com os alunos, mas apresentando a realidade de que irão enfrentar desafios ao longo de suas vidas.

Compreende-se de condições objetivas que participam as instituições de ensino, principalmente as escolas públicas, pois, precisam estar sempre atualizadas e ter um nível de qualidade, mas na realidade são poucas as escolas de rede pública que possuem essa especificação.

Se as escolas de âmbito público tivessem qualidade, os pais com condições financeiras melhores, não optariam em colocar seus filhos nas escolas particulares, que possuem um ensino 
Id on Line Revista Multidisciplinar e de Psicologia

Id on Line Multidisciplinary and Psycology Journal

educacional mais elevado, afinal ela se manterá no mercado se apresentar resultado bons quanto aos seus alunos.

Mudanças devem ser feitas com urgência para qualificar e garantir um ensino melhor aos alunos, afinal, todos devem ter uma educação de qualidade e para que isso ocorra seria necessária uma reforma quanto a administração nacional, onde realmente os recursos destinados a educação aumentem, mas que sejam direcionados de forma correta.

Atualmente os pais com condições financeiras acessível colocam seus filhos em escolas particulares com valores elevados pela qualidade que possuem, objetivando que seus filhos entrem nas melhores faculdades/universidades, justamente pelo bom ensino que tiveram, ao saírem do ensino superior já estejam aptos ao mercado de trabalho.

O que podemos perceber é uma precariedade de ensino, onde os gestores escolares não possuem capacitação a nível para que possam inserir novos métodos pedagógicos nas escolas que direcionam. A educação é a prioridade, um bom ensino e interação do colégio e a sociedade.

No papel de gestor é a função de cada membro daquela história, onde cada um exerce uma parte importante, começando pela diretoria escolar que é responsável por coordenar a sua equipe para que faça um trabalho adequado e de eficiência. Ou seja, uma organização interna com planos e objetivos é de fundamental importância para que os alunos tenham um bom aprendizado.

Essa gestão deve ser elaborada sempre dentro da atualidade, não apenas estar em sala de aula, mas uma interação com os pais e com os alunos, para que haja um incentivo visando sempre a melhoria e evolução educacional, uma ligação entre as partes envolvidas.

Poucas são as escolas que aderem esse modelo de sociabilidade, o que ocorre é uma rotina normal, aonde as crianças vão as escolas, cumprem o horário e voltam para suas casas, não existem a interação adequada entre a escola e os país, onde ambos poderiam auxiliar em uma boa educação e interação quanto aos incentivos para aquela criança.

Outro fator importante é a inclusão dos adultos dentro das escolas, uma gestão que é muito importante, mas a qualidade do ensino passado aos adultos é o que não é tão qualificado, o projeto politico pedagógico deve ser incluso também com os jovens e adultos, para estimular que concluam seus estudos.

A gestão escolar é importante manter sua base aliada, diretores, coordenadores, professores, funcionários, alunos e pais, para a construção do Projeto Político Pedagógico que 
Id on Line Revista Multidisciplinar e de Psicologia

Id on Line Multidisciplinary and Psycology Journal

será relatado minuciosamente no decorrer deste trabalho, importante também que cada um da equipe precisa saber a importância desse projeto e seu funcionamento.

\section{Conceito do Projeto Político Pedagógico}

Ele surgiu logo após a Constituição de 1988, para dar autonomia de criação da identidade escolar, seu marco político é a Lei de Diretrizes Brasileiras (LDB). Para planejar e construir um Projeto Político Pedagógico, a escola precisa ter um compromisso sério com a educação, sendo essa de qualidade, visto que os principais agentes desse projeto são a escola e a comunidade, sem essa aliança, não há o que se falar de PPP.

É um documento projetado que será posto em pratica que propõe uma maneira organizada do trabalho pedagógico, com o intuito de solucionar os problemas e buscando relações sociais sem competição, apenas apresentando através de sua autonomia a gestão interna das escolas, a maior missa da escola é a educação, preparar os educandos para que estes estejam aptos e com responsabilidade pela evolução e transformação da sociedade, afinal, a educação é a base fundamental para que se tenha sucesso em vários aspectos da vida.

No sentido etimológico, o termo projeto vem do latim projectu, particípio passado do verbo projicere, que significa lançar para diante. Plano, intento, desígnio. Empresa, empreendimento. Redação provisória de lei. Plano geral de edificação (Ferreira 1975, p. 1.144).

Todo projeto supõe rupturas com o presente e promessas para o futuro. Projetar significa tentar quebrar um estado confortável para arriscar-se, atravessar um período de instabilidade e buscar uma nova estabilidade em função da promessa que cada projeto contém de estado melhor do que o presente. Um projeto educativo pode ser tomado como promessa frente a determinadas rupturas. As promessas tornam visíveis os campos de ação possível, comprometendo seus atores e autores. (Gadotti, 1994, p. 579).

A interpretação quanto ao conceito do projeto pedagógico já está bem apresentada, mas o que intriga é onde entra o lado político neste projeto de tamanha importância, justamente por estar interligado com o compromisso sociopolítico, com interesses reais e coletivos, onde o interesse da maioria prevalece.

O sentido político em ter compromisso com a formação educacional do cidadão para a sociedade, enquanto o projeto pedagógico vai se realizando, ou seja, sai do papel e vira uma 
Id on Line Revista Multidisciplinar e de Psicologia

Id on Line Multidisciplinary and Psycology Journal

prática, uma realidade, neste momento estará sendo realizado o papel político, que visa beneficiar todos, a efetivação dos planejamentos pedagógicos nas escolas, formando cidadãos responsáveis, preparados para entrar nas melhores faculdades e então saírem prontos para o mercado de trabalho.

O projeto político pedagógico possui uma parceria entre si, onde ao se realizar um o outro consequentemente estará fazendo e cumprindo com o seu papel, uma reflexão e discussão dos problemas internos escolares para realizarem um serviço adequado à comunidade. Cumprem juntos os seus propósitos e a intenção de execução de seus planos.

Quando uma escola decide pela qualidade de seu ensino, criar um PPP, ela precisa estar ciente de um bom relacionamento com a comunidade, ela adere concepções participativas, restaurando princípios fundamentais e construindo novos conhecimentos.

"O projeto é um documento que propõe uma direção política e pedagógica para o trabalho escolar, formula metas, prevê as ações, institui procedimentos e instrumentos de ação." LIBÂNEO (2005, p.345).

Quando se fala em educação, instantaneamente nos vem em mente conhecimento e escola, justamente neste último que entra o projeto político pedagógico, definindo qual a identidade das escolas, informando e auxiliando as escolas quanto ao ensino de qualidade e adequado.

A escola em si, com um conceito que já temos em mente, seria o ensino e um professor, ou seja, cumprir os horários, fazer testes, ser aprovado ou não, mas o intuito deste projeto é uma inclusão cultural nas escolas, uma interação entre toda a escola e a comunidade, uma atração, uma forma de fazer com que os alunos mantenham um interesse em participar daquele local.

O Projeto Político Pedagógico é a identidade, é a "Constituição" da escola. Ele é político porque é um compromisso social, já que se compromete com a formação do cidadão para um tipo de sociedade que se deseja e é Pedagógico porque define as ações educativas e as características necessárias à escola para que ela cumpra seu propósito. Um PPP deve contemplar a missão da escola (ou marco referencial), que é a declaração explícita dos valores e aspirações da escola. (Furtado, 2015).

O Projeto Político Pedagógico deve ser objetivo escolar porque garante que a escola esteja relacionada aos propósitos divergentes, ajudando com uma reforma na definição de todos na escola, sendo uma estratégia para que exista uma ligação entre a sociedade e esta última, um envolvimento de ambas as partes para que a educação avance quanto aos novos paradigmas positivos inseridos no âmbito escolar. 
O Projeto Político Pedagógico (PPP) é uma oportunidade que a equipe escolar coordenação pedagógica e os demais membros da comunidade escolar podem tomar nas mãos as rédeas de sua escola, definindo através dele o tipo de gestão que terão as ações, os objetivos a serem alcançados a partir dessas ações. Além de possibilitar que as experiências de cada um sejam valorizadas e usadas na busca de uma educação democrática, inclusiva e de qualidade. (Perônico, 2009).

É a inclusão pedagógica nas escolas, um respeito com essa palavra, teoria e pratica que estimulem um relacionamento educacional entre os professores (assim como toda a equipe escolar) e seus alunos (a comunidade de modo amplo). Sendo um projeto que precisa de cuidado no planejamento, incluindo possibilidades e orientações que serão compartilhados entre todos os integrantes.

Construído participativamente, é uma tentativa, no âmbito da educação, de resgatar o sentido humano, científico e libertador do planejamento. (...) Pode ser entendido como a sistematização, nunca definitiva, de um processo de Planejamento Participativo, que se aperfeiçoa e se concretiza na caminhada, que define claramente o tipo de ação educativa que se quer realizar. É um instrumento teórico-metodológico para a transformação da realidade. É um elemento de organização e integração da atividade prática da instituição nesse processo de transformação. (Vasconcellos, 1995, p 143).

Quando o Projeto Político Pedagógico é aderido pela escola é importante lembrar que ele deve ser posto em prática, um sistema com inúmeros pontos positivos e que se forem executados de forma correta o resultado obtido será em prol de um bom ensino e convivência entre as parte envolvidas.

Um projeto é um esforço temporário empreendido cujo objetivo é criar um novo produto, serviço ou processo. O Projeto Político Pedagógico (PPP) é um instrumento que reflete a proposta educacional da escola. É através dele que a comunidade escolar pode desenvolver um trabalho coletivo, cujas responsabilidades pessoais e coletivas são assumidas para execução dos objetivos estabelecidos. (INFOESCOLA, 2006).

Esse projeto surgiu com um objetivo bem exato, com uma aliança e compromisso com a formação educacional de cada indivíduo, relacionando a sociedade com o âmbito pedagógico, assim as escolas cumpram o propósito e finalidade de sua existência, definindo as ações educativas e suas principais características.

Este documento possui uma base de diretrizes e ações do processo educacional para que possa ser desenvolvido na escola, afinal, seu objetivo é um trabalho pedagógico direcionado a ela, com exigências positivas e corretas dentro do sistema educacional, assim como uma 
Id on Line Revista Multidisciplinar e de Psicologia

Id on Line Multidisciplinary and Psycology Journal

necessidade de cooperação da escola, envolvendo também a cultura que contribuirá para modifica-la.

\section{Importância do Projeto Político-Pedagógico}

É um projeto de fundamental importância para a educação nacional, sendo o planejamento interno das instituições educacionais, o PPP irá apresentar o que a escola idealiza seus objetivos, fundamentos e apresentando o que plano de elaboração de suas metas para coloca-las em prática.

A importância do projeto político-pedagógico está no fato de que ele passa a ser uma direção, um rumo para as ações da escola. É uma ação intencional que deve ser definida coletivamente, com consequente compromisso coletivo. (BETINI, 2005).

Ele tem como principal função a idealização de um projeto com elaboração de ações pedagógicas com o objetivo de solucionar os problemas de aprendizagem que são apresentados por cada instituição, com a participação de toda a equipe que está envolvida no processo, visando às melhorias de qualidade de ensino para o desenvolvimento do texto pedagógico e de técnicas estimativas voltadas ao campo educacional de ensino.

Segundo Picoli e carvalho (2007, p.4), "O projeto precisa ser conhecido, discutido e reformulado sempre em concordância com as políticas públicas educacionais vigentes, sem perder a análise crítica da realidade que se manifesta a nível micro, mas que é reflexo da realidade globalizada".

O planejamento é a base fundamental do Projeto Político Pedagógico e precisa de uma analise minuciosa e uma reflexão de como está sendo elaborados seus fundamentos, sendo implantado e avaliado, contribuindo diretamente para que os objetivos sejam alcançados, então o PPP contribui com novas maneiras e métodos de aprendizagem e um bom relacionamento com a sociedade.

Os Projetos Políticos Pedagógicos começaram a ser utilizados com frequência pelas instituições com a publicação da Lei de Diretrizes e Bases de Educação Nacional, sendo obrigatória uma proposta abordando o método pedagógico a ser utilizado na educação básica.

Um projeto é um esboço que será posto em pratica, uma avaliação do que será feito, uma direção que será seguida, no caso pedagógico, as ações escolares, uma ação com intenção 
que deve ser definida em coletividade. Escolhas com prioridades na formação do cidadão e seu futuro, atividades didáticas que serão impostas nas escolas, contribuindo com as prioridades escolares.

Há uma necessidade quanto a escola implantar sua autonomia e este projeto serve como um norteador para apresentar os princípios que regem a função e finalidade pedagógica dela, isso não significa que será tudo de forma rápida, ou seja, aderindo ao projeto e já executando, precisa de uma analise minuciosa para que possa ter a finalidade objetivada.

É importante dar abrangência e ampliar cada vez mais o projeto nas escolas, focalizando a educação como base para a solução de muitos problemas no Brasil, um instrumento responsável pela organização e aliança entre as escolas e a comunidade, significando a transformação do espaço escolar, práticas e formas de organizar e administrar o trabalho pedagógico interno da escola.

Veiga já defendia o projeto politico pedagógico em suas doutrinas, afirmando que a sua construção estava assegurada pelas concepções da sociedade, educação e instituição, uma individualização para o bem de todos, ou seja, a formação de cada indivíduo que seria uma recompensa pessoal e afetando positivamente a sociedade.

\footnotetext{
É um instrumento de trabalho que mostra o que vai ser feito, quando, de que maneira, por quem para chegar a que resultados. Além disso, explicita uma filosofia e harmoniza as diretrizes da educação nacional com a realidade da escola, traduzindo sua autonomia e definindo seu compromisso com a clientela. É a valorização da identidade da escola e um chamamento à responsabilidade dos agentes com as racionalidades interna e externa. Esta ideia implica a necessidade de uma relação contratual, isto é, o projeto deve ser aceito por todos os envolvidos, daí a importância de que seja elaborado participativa e democraticamente. (VEIGA, 2001, p.110).
}

É preciso um tempo adequado para que o projeto deixe de ser apenas um projeto e passe para a prática, uma elaboração do documento, para que seja seguido por todos, principalmente pelos professores, para que seja possível garantir a funcionalidade e execução adequada, impedindo que equívocos sejam cometidos tanto na organização quanto no pedagógico.

Nota-se a grande importância que tem o professor no projeto em tese, inclusive na necessidade de atender o grande número de alunos e dar as respostas aos questionamentos que são lançados, a escola deve tirar os professores da rotina, dando a eles autonomia de expandir e trabalhar com o ensino pedagógico, ou seja, esse processo ser incluído cada vez mais nas escolas. 
Id on Line Revista Multidisciplinar e de Psicologia

Id on Line Multidisciplinary and Psycology Journal

O PPP visa garantir a participação efetiva dos vários segmentos nas ações educativas, para tanto, precisa ser flexível e estar sempre em processo de conclusão, proporcionando a melhoria da escola também nos seus aspectos administrativos e financeiros, através da reflexão periódica da prática pedagógica por todos.

\section{Considerações Finais}

O que foi proposto no presente trabalho foi apresentar um cenário atual da educação e do ensino brasileiro, juntamente com um projeto relacionado a implantação da cultura e envolvimento da sociedade junto a escola, propondo uma aliança e uma forma de incluir na educação brasileira métodos atrativos de ensino.

Obviamente os métodos atrativos são justamente com o intuito de que os jovens saiam preparados da escola para entrarem nas faculdades e ao concluírem essa etapa, não apenas sair com mais um diploma, e sim, apto a entrar e se destacar no mercado de trabalho, fazendo a grande diferença para a sociedade.

A educação e o método de ensino utilizado no Brasil sofreram muitas alterações com o passar do tempo, incluído no texto Constitucional a garantia da educação a todos, onde é dever do Estado garantir que todos tenham acesso e gratuito, ou seja, as crianças e adolescente são obrigados a frequenta a escola, assim como participar das atividades escolares.

O acesso a escola por todos que a procuram, não é apenas isso, mas a garantia do Estado pela qualidade do ensino, pois, essa qualidade é o que não tem acontecido no sistema brasileiro de educação, essa é uma essência para que a escola ganhe destaque, em formar jovens capacitados para entrarem nas melhores faculdades e ao saírem delas, se destaquem e realmente estejam prontos para entrarem no mercado de trabalho como os melhores.

É importante que a escola desenvolva em sua avaliação ou em suas atividades a inclusão da cultura, diferenciando o que é de praxe que aconteça, não apenas se direcionando as avaliações, que afinal, é um processo que existe há muitos anos, mas a forma de aderir meios pedagógicos para que todos sejam envolvidos e haja interesse escolar por meio das crianças e adolescentes.

O processo de socialização entre a escola e a comunidade forma valores sólidos e conscientes no papel social da primeira, não basta apenas saber sobre a realidade, mas utilizar 
Id on Line Revista Multidisciplinar e de Psicologia

Id on Line Multidisciplinary and Psycology Journal

seu poder escolar para auxiliar, assim como para quem aprende, utilizar o conhecimento adquirido como um instrumento de transformação, construindo e dando oportunidade de uma mudança e um futuro mais solidário, onde todos contribuem para a construção de uma cultura comum.

Para considerar e ter um objetivo alcançado fica explicito a importância de definir o projeto em questão, apresentando a sua importância tanto para os membros da escola, quando para os alunos e a comunidade, a gestão escolar seja democrática, ou seja, todos sempre envolvidos nos atos do projeto, a organização escolar e assim o projeto político pedagógico seja executado.

\section{Referências}

ARRUDA, Marcos e BOFF, Leonardo. Globalização - Desafios sócio econômicos, éticos e educativos. Petrópolis, RJ: Vozes, 2000.

BETINI, Geraldo Antônio. A Construção do Projeto Político Pedagógico da Escola. EDUC@ação - Rev. Ped. - UNIPINHAL - Esp. Sto. do Pinhal - SP, v.01, n. 03, jan./dez. 2005.

FERREIRA, Aurélio Buarque de Holanda. Novo Dicionário da Língua Portuguesa. Rio de Janeiro, Nova Fronteira, 5 ed., p. 1.144.

GADOTTI, Moacir. "Pressupostos do projeto pedagógico". In: MEC, Anais da Conferência Nacional de Educação para Todos. Brasília, 28/8 a 2/9/94.

LIBÂNEO, J. C.; OLIVEIRA, J.F de; TOSCHI. Educação escolar: política, estrutura e organização. 2. Ed. São Paulo: Cortez, 2005.

LÜCK, H. [et al]. A escola participativa: o trabalho do gestor escolar. 5ed. Rio de Janeiro: DP\&A, 2001

MARTINS, Rosilene Maria Sólon Fernandes. Direito á Educação: aspectos legais e constitucionais. Rio de Janeiro: Letra Legal, 2004.

MUNIZ, Regina Maria Fonseca. O direito à educação. Rio de Janeiro: Renovar, 2002.

PADILHA, Paulo Roberto. Planejamento dialógico: Como construir o projeto político pedagógico da escola. São Paulo: Cortez, 2007. 
PICOLI, E. S. A.; CARVALHO, E. J. G. Projeto político-pedagógico: uma construção "coletiva"? III Encontro de Pesquisa em Educação, I Jornada de Gestão Escolar e XV Semana de Pedagogia - Pedagogia 35 anos: História e Memória. UEM, Maringá, 2008.

SILVA, José Afonso. Curso de Direito Constitucional Positivo. 18.ed. São Paulo: Malheiros Editores, 2000.

VASCONCELLOS, Celso dos Santos. Planejamento: projeto de ensino- aprendizagem e projeto político-pedagógico. 10. ed. São Paulo: Libertad, 2002.

VEIGA, Ilma Passos A. (Org). Projeto Político Pedagógico da Escola: uma construção possível. 3 ed. Campinas: Papirus Editora, 1995.

Como citar este artigo (Formato ABNT):

NOGUEIRA, M.Z..L.; BRITO, S.M.F. Projeto Político Pedagógico: Uma estratégia para o sucesso da Gestão Escolar. Id on Line Revista Multidisciplinar e de Psicologia, Janeiro de 2017, vol.10, n.33, p. 300-319. ISSN: 1981-1179.

Recebido: 06/12/2016

Aceito: $08 / 12 / 2016$ 